\title{
Pengaruh Kualitas Jasa terhadap Kepuasan Pelanggan di Prima Elektronik Medan
}

\author{
Stephanie $^{1}$, Weny ${ }^{2, *}$, Yuliana ${ }^{2}$, William Vincent ${ }^{2}$, Fahmi Sulaiman ${ }^{3}$ \\ ${ }^{1}$ Program Studi Manajemen Pemasaran, Politeknik Cendana, Medan, Indonesia \\ ${ }^{2}$ Program Studi Manajemen Perusahaan, Politeknik Cendana, Medan, Indonesia \\ ${ }^{3}$ Program Studi Manajemen Perusahaan, Sekolah Tinggi Ilmu Manajemen Sukma, Medan, Indonesia \\ Email: 2,*estindo@gmail.com
}

\begin{abstract}
Abstrak-Meningkatnya intensitas persaingan menuntut perusahaan untuk selalu memperhatikan dan berusaha memenuhi kebutuhan dan keinginan pelanggan dengan cara memberikan jasa yang lebih baik dari yang dilakukan oleh pesaing. Jasa didefinisikan sebagai suatu kinerja penampilan, tidak berwujud dan cepat hilang, lebih dapat dirasakan dari pada dimiliki, serta konsumen dapat langsung mengonsumsi jasa tersebut. Kualitas Jasa yang terbaik akan menimbulkan kepuasan pelanggan. Selain itu, menciptakan dan membangun kepercayaan konsumen juga merupakan salah satu faktor yang paling penting dalam menciptakan loyalitas konsumen. Loyalitas mengarah pada pembelian yang berulang, perekomendasian, dan proporsi pembelanjaan yang meningkat. Prima Elektronik merupakan badan usaha yang bergerak dibidang jasa perbaikan komputer dan printer pada produk merek HP (Hewlett Packard) dan sudah dipercaya menjadi sebuah Service Center HP di Kota Medan. Tujuan pelaksanaan penelitian ini adalah untuk mengetahui pengaruh Kualitas Jasa terhadap Kepuasan Pelanggan di Prima Elektronik Medan. Hasil penelitian menunjukkan bahwa kualitas jasa berpengaruh terhadap kepuasan pelanggan di Prima Elektronik Medan.Dalam R square (R2) menunjukkan koefisien determinasi adalah sebesar 67\% dimana variabel Kualitas Jasa dapat menjelaskan variabel Kepuasan Pelanggan, sedangkan sisanya sebesar 33\% dijelaskan oleh variabel lain yang tidak diteliti oleh penelitian ini. Sebagai saran, Prima Elektronik diharapkan untuk terus meningkatkan kualitas jasa agar dapat mencapai kepuasan pelanggan sehingga tercapai tujuan organisasi.
\end{abstract}

Kata Kunci: Jasa; Kualitas Jasa; Kepuasan Pelanggan; Kepercayaan; Loyalitas

Abstract-The increasing intensity of competition requires companies to always pay attention and try to meet the needs and desires of customers by providing better services than competitors. Service is defined as an appearance performance, intangible and quickly lost, more can be felt than owned, and consumers can directly consume the service. The best service quality will lead to customer satisfaction. In addition, creating and building consumer trust is also one of the most important factors in creating consumer loyalty. Loyalty leads to repeat purchases, recommendations, and an increased proportion of purchases. Prima Elektronik is a business entity engaged in computer and printer repair services for HP brand products (Hewlett Packard) and has been trusted to be an HP Service Center in Medan City. The purpose of this research is to determine the effect of Service Quality on Customer Satisfaction at Prima Elektronik Medan. The results show that service quality affects customer satisfaction at Prima Elektronik Medan. In R square (R2) shows the coefficient of determination is $67 \%$ where the Service Quality variable can explain the Customer Satisfaction variable, while the remaining $33 \%$ is explained by other variables not examined. by this research. As a suggestion, Prima Elektronik is expected to continue to improve the quality of services in order to achieve customer satisfaction so that organizational goals can be achieved.

Keywords: Service; Service Quality; Customer Satisfaction; Trust; Loyalty

\section{PENDAhUluan}

Pada zaman sekarang ini, persaingan di dunia bisnis kian meningkat. Setiap perusahaan akan menghadapi persaingan yang ketat. Bukan hanya perusahaan yang sudah bertaraf Internasional dan Go Public saja tetapi usaha kecil menengah pun juga mengalami persaingan. Dalam dunia usaha yang bersifat dinamis, selalu mengalami perubahansetiap saat. Sehingga pemasaran mempunyai peranan yang sangat penting untuk keberhasilan perusahaan. Pemasaranmerupakan salah satu faktor penting guna menjaga kelangsungan hidup perusahaan yang menghadapi persaingan(Yuliana, Lisa, Nancy, Chandra, \& Aigan, 2019). Banyaknya industri yang berkembang di Indonesia saat ini harus didukung oleh manajemen yang baik dan disiplin, agar mampu bertahan dalam persaingan dunia industri(Anggraini, Dennius, Arwin, Ciamas, \& Wilinny, 2019). Meningkatnya intensitas persaingan dan jumlah pesaing menuntut perusahaan untuk selalu memperhatikan kebutuhan dan keinginan pelanggan serta berusaha untuk memenuhi harapan dan keinginan pelanggan dengan cara memberikan jasa atau pelayanan yang lebih memuaskan dan lebih baik daripada yang dilakukan oleh pesaing.Setiap karyawan perusahaan dituntut agar dapat bekerja efektif, efisien, kualitas dan kuantitas pekerjaannya baik sehinggadaya saing perusahaan semakin besar(Weny, Nugroho, Anggraini, Sofian, \& Erwin, 2019). Dengan lebih memperhatikan aspek tersebut tentunya tujuan yang ingin dicapai akan terwujud.Perusahaan tidak hanya harus mampu mempertahankan pelanggan namun bahkan harus mampu meningkatkan jumlah konsumennya. Kualitas Jasa yang terbaik akan menimbulkan kepuasan dari pelanggan. Kualitas berkaitan erat dengan Kepuasan Pelanggan karena memberikan dorongan khusus bagi para pelanggan untuk menjalin ikatan relasi saling menguntungkan dalam jangka panjang dengan perusahaan dan karena adanya kepuasan pelanggan maka perusahaan dapat menarik konsumen baru dan pemakaian jasa secara rutin dengan begitu perusahaan tetap dapat mencapai tujuan utamanya yaitu mendapatkan laba/ keuntungan. Kualtas jasa merupakan hal yang sangat penting dalam peningkatan penjualan(Sulaiman, 2017)

Kepuasan konsumen terhadap suatu barang atau jasa produk tertentu tergantung pada beberapa faktor seperti besarnya biaya untuk berpindah ke produk barang atau jasa yang lain, adanya kesamaan mutu, kualitas, atau pelayanan dari jenis barang atau jasa pengganti, adanya resiko perubahan biaya akibat barang atau jasa pengganti, dan berubahnya tingkat kepuasan yang didapat dari produk baru dibanding dengan pengalaman terhadap produk sebelumnya yang pernah dipakai(Rohaeni \& Marwa, 2018). 
Bila seorang pelanggan menyatakan puas, belum tentu kepuasannya itu dapat berlangsung terus-menerus di waktu yang akan datang. Oleh karena itu, kepuasan ini hanya bersifat jangka pendek. Jika ingin mempertahankannya, maka harus selalu dilakukan pencarian nilai pelanggan terutama untuk masa yang akan datang, serta melengkapinya dengan cara menganalisa Kepuasan Pelanggan. Artinya dengan berubahnya nilai pelanggan yang terus-menerus, perusahaan harus mengikutinya dengan menyediakan produk atau jasa yang sesuai dengan kebutuhan pelanggannya.

Prima Elektronik yang sudah berdiri sejak tahun 2004 dan merupakan badan usaha yang bergerak dibidang jasa perbaikan komputer dan printer pada produk merek HP (Hewlett Packard) dan sudah dipercaya menjadi sebuah Service Center HP di Kota Medan. Prima Elektronik sendiri sudah melakukan perbaikan terhadap beberapa produk HP seperti Notebook (Laptop), Printer, PC AIO/CPU dan Tablet yang dapat diproses secara klaim garansi ataupun tidak garansi yang dimana jangka waktu garansi terbatas bagi produk-produk HP. Dalam jangka waktu yang disebutkan dan ditentukan mulai dari tanggal pembelian unit tersebut, yang mana tanggal invoice pembelian tersebut dihitung sampai dengan satu tahun atau dua tahun setelah pembelian tergantung dari tipe produk yang dibeli oleh Pelanggan.

Selama masa pandemic Covid19 ini memaksa beberapa orang melakukan semua kegiatan berbasis online, maka diperlukan alat komunikasi seperti handphone dan komputer untuk menunjang kegiatan orang banyak. Sampai pada tahap new normal yang sudah dilakukan dibeberapa bagian kota di Indonesia terutama Medan membuat customer beramairamai datang ke HP Service Center untuk menggunakan jasa perbaikan pada komputer dan printer mereka yang sedang mengalami masalah karena telah lama tidak digunakan atau karena faktor lain.

Tujuan pelaksanaan penelitian ini adalah untuk mengetahui Pengaruh Kualitas Jasa terhadap Kepuasan Pelanggan di Prima Elektronik, Medan. Variabel X didalam penelitian ini adalah Kualitas Jasa dengan indikator yang digunakan terdiri dari Reliabilitas, Daya Tanggap, Jaminan, Empati dan Bukti Fisik(Tjiptono \& Chandra, 2019). Sedangkan Variabel Y didalam penelitian ini adalah Kepuasan Pelanggan dengan indikator yang digunakan terdiri dari Kualitas Produk, Kualitas Pelayanan, Emosional, Harga dan Biaya(Indrasari, 2019).

\section{KERANGKA TEORI}

Kualitas jasa adalah tingkat keunggulan yang diharapkan untuk pengendalian atas tingkat keunggulan tersebut untuk memenuhi keinginan pelanggan. Kualitas jasa yang sesuai dengan harapan pelanggan sangat penting bagi perusahaan untuk dapat memenangkan persaingan(Winata \& Fiqri, 2017).

Kualitas pelayanan yaitu pemenuhan kebutuhan konsumen berdasarkan tingkat keunggulan dari produk dan jasa yang sesuai dengan harapan sehingga dapat memenuhi keinginan para konsumen(Rohaeni \& Marwa, 2018).

Kepuasan konsumen yaitu tingkat perasaan senang atau kecewa setelah membandingkan jasa/produk yang diterima dan yang diharapkan(Zulkarnaen \& Amin, 2018).

Kepuasan konsumen merupakan salah satu elemen penting dalam peningkatan kinerja pemasaran dalam suatu perusahaan. Kepuasan yang dirasakan oleh pelanggan dapat meningkatkan intensitas membeli dari pelanggan tersebut. Dengan terciptanya tingkat kepuasan pelanggan yang optimal maka mendorong terciptanya loyalitas di benak pelanggan yang merasa puas tadi. Kepuasan diukur dari sebaik apa harapan pelanggan dipenuhi. Sedangkan loyalitas pelanggan adalah ukuran semau apa pelanggan melakukan pembelian lagi(Setyo, 2017).

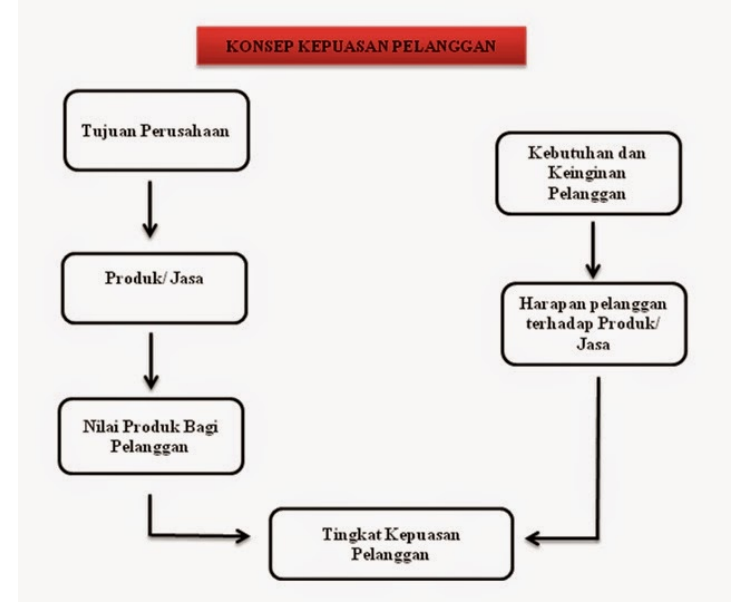

Gambar 1. Konsep Kepuasan Pelanggan

\section{METODOLOGI PENELITIAN}

Peneliti akan menggunakan dan berfokus pada metode penelitian kuantitatif untuk proses penelitian ini. Yang mana definisi metode kuantitatif adalah metode penelitian yang bertujuan menggambarkan atau menganalisis bagaimana fenomena atau gejala sosial yang terjadi di masyarakat saling berhubungan satu sama lain. Lokasi penelitian ini adalah Prima Elektronik yang beralamat di jalan Asia No. 360 F, Medan. Penelitian dilakukan mulai dari bulan Februari 2021 
sampai dengan bulan Juli 2021. Populasi dalam penelitian ini adalah pelanggan Prima Elektronik Medan yang telah berlangganan lebih dari satu kali yaitu sebanyak 25 pelanggan yang tercatat pada bulan Maret sampai Juli 2021. Sampel penelitian ini adalah 25 pelanggan Prima Elektronik Medan. Peneliti menggunakan sampling jenuh di mana keseluruhan anggota populasi dipilih sebagai sampel penelitian.

Dalam penelitian ini yang menjadi sumber data primer meliputi hasil pengisian kuesioner yang dibagikan kepada responden mengenai permasalahan dan data yang dibutuhkan dalam penelitian ini. Sedangkan yang menjadi sumber data sekunder dalam penelitian ini adalah data yang diperoleh dan diolah dari sumber Prima Elektronik seperti profil perusahaan, struktur organisasi maupun data yang diperoleh dari buku, teori-teori serta internet yang berkenaan dengan penelitian yang dilakukan. Teknik pengumpulan data yang digunakan oleh peneliti adalah kuesioner dengan skala pengukuran menggunakan skala Likert, wawancara dan dokumentasi.

\subsection{Uji Validitas dan Reliabilitas Alat Ukur Penelitian}

Hasil penelitian yang valid bila terjadi kesamaan antara data yang terkumpul dengan data yang sesungguhnya terjadi pada objek yang diteliti. Selanjutnya, hasil penelitian yang reliabel, bila terdapat kesamaan data dalam waktu yang berbeda.

\subsection{Uji Normalitas}

Uji normalitas digunakan untuk menguji data variabel bebas (X) dan data variabel terikat (Y) pada persamaan regresi yang dihasilkan berdistribusi normal atau berdistribusi tidak normal.

\subsection{Uji Linieritas}

Uji linieritas sering digunakan sebagai prasyarat apabila akan dilakukan analisis korelasi atau regresi linier. Syarat pengambilan keputusan pada uji linieritas adalah apabila dua variabel mempunyai nilai signifikan (sig. Deviation from linearity) lebih besar dari 0,1 maka dapat dikatakan kedua variabel adalah linear.

\subsection{Metode Analisis Data}

a. Korelasi

Koefisien korelasi (R) adalah untuk mengetahui kuat atau tidaknya hubungan antara satu variable dengan variabel yang lain.

b. Koefisien Determinasi

Analisis determinasi atau disebut juga $R$ Square yang disimbolkan dengan R2 digunakan untuk mengetahui besaran pengaruh variable independen $(\mathrm{X})$ secara bersama-sama terhadap variable dependen $(\mathrm{Y})$ dimana semakin kecil nilai koefisien determinasi. Hal ini berarti pengaruh variable independen (X) terhadap variable dependen (Y) semakin lemah. Sebaliknya, jika nilai koefisien determinasi semakin mendekati angka 1, makapengaruh variable independen terhadap variable dependen semakin kuat.

c. Regresi Linear Sederhana

Analisis regresi bertujuan untuk memprediksi nilai variabel dependen dengan adanya perubahan variabel independen.

Adapun persamaannya adalah sebagai berikut (1) :

$\mathrm{Y}=\mathrm{a}+\mathrm{bX}$

Dimana :

$\mathrm{Y}=$ Variabel terikat

$\mathrm{X}=$ Variabel bebas

$\mathrm{b}=$ Koefisien regresi

$\mathrm{a}=$ Konstanta

\subsection{Uji Hipotesis (Uji T)}

Uji Signifikansi Parameter Individual (Uji Statistik t) mengetahui kemampuan dari variabel independen secara individu dalam menjelaskan peilaku variabel dependen. Pengujian dilakukan dengan menggunakan tingkat signifikansi 0,05. Jika nilai signifikansi kurang atau sama dengan 0,05 maka hipotesis diterima. Jika nilai signifikansi lebih dari 0,05 maka hipotesis ditolak(In Khurun \& Asyik, 2019).

\section{HASIL DAN PEMBAHASAN}

Tabel 1. Hasil Uji Validitas

Item-Total Statistics

\begin{tabular}{lrrrr}
\hline & $\begin{array}{c}\text { Scale Mean if } \\
\text { Item Deleted }\end{array}$ & $\begin{array}{c}\text { Scale Variance if } \\
\text { Item Deleted }\end{array}$ & $\begin{array}{c}\text { Corrected Item- } \\
\text { Total Correlation }\end{array}$ & $\begin{array}{c}\text { Cronbach's Alpha } \\
\text { if Item Deleted }\end{array}$ \\
\hline KualitasJasa & 41,64 & 8,490 &, 819 \\
KepuasanPelanggan & 42,20 & 8,083 &, 819 \\
\hline
\end{tabular}


Berdasarkan tabel 1 di dibawah ini diperoleh nilai Corrected Item-Total Correlation ( $\mathrm{r}_{\text {hitung }}$ ) pada variabel Kualitas Jasa adalah 0,819 dan Kepuasan Pelanggan adalah 0,819, dimana akan diperoleh hasil kedua variabel $r_{\text {hitung }} 0,819>r_{\text {tabel }} 0,396$. Sehingga dapat disimpulkan bahwa kedua variabel yaitu Kualitas Jasa dan Kepuasan Pelanggan adalah valid karena nilai $r_{\text {hitung }}>r_{\text {tabel. }}$.

Tabel 2. Hasil UjiReliabilitas

Reliability Statistics

\begin{tabular}{rrr}
\hline Cronbach's Alpha & N of Items & \\
\hline, 900 & & 2 \\
\hline
\end{tabular}

Hasil uji reliabilitas tersebut menunjukan bahwa kedua variabel yaitu Kualitas Jasa dan Kepuasan Pelanggan memiliki nilai cronbach alpha> 0,60 dimana nilai cronbach alpha Kualitas Jasa dan Kepuasan Pelanggan adalah 0,900 $>0,60$, sehingga dapat disimpulkan bahwa variabel Kualitas Jasa dan Kepuasan Pelanggan dinyatakan reliabel yang berarti bahwa kuesioner layak digunakan sebagai alat ukur.

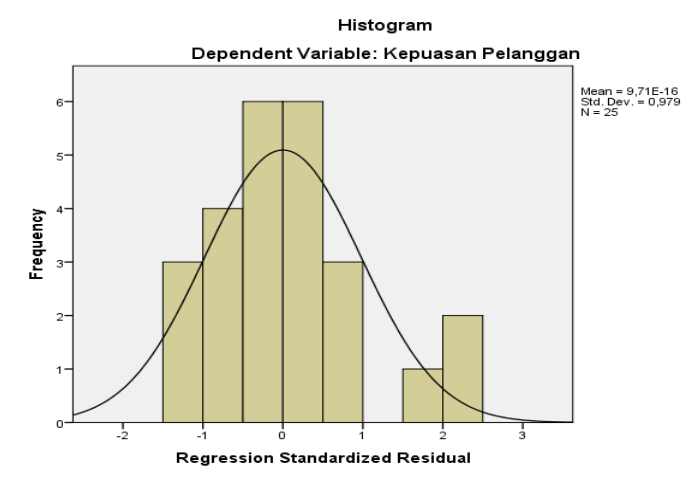

Gambar 2. Histogram Uji Normalitas

Berdasarkan gambar 2 dapat diketahui bahwa variabel berdistribusi menunjukan hasil yang normal, hal ini dapat ditunjukan oleh data tersebut yang membentuk gambar menyerupai lonceng. Data variabel distribusi yang ditampilkan menunjukkan hasil uji statistik yang tidak melanggar asumsi yang berarti menunjukkan hasil yang valid.

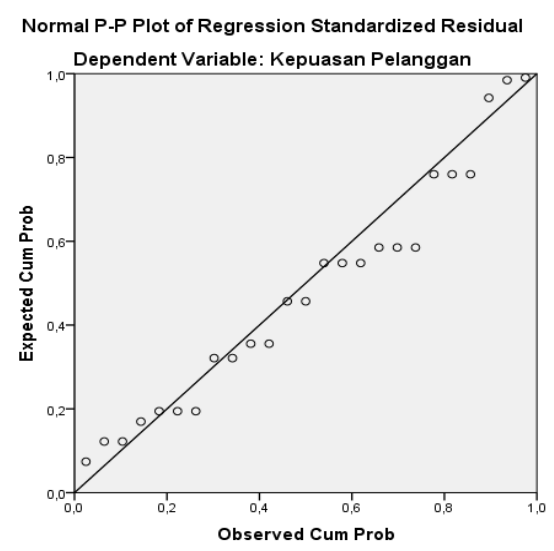

Gambar 3. Plot Uji Normalitas

Berdasarkan grafik P-Plot dapat diketahui bahwa variabel berdistribusi menunjukan hasil yang normal, hal ini dapat ditunjukan oleh data tersebut yang tidak melenceng ke kiri atau ke kanan, sedangkan pada gambar di atas juga dapat terlihat titik yang mengikuti data disepanjang garis diagonal, hal ini berarti data berdistribusi normal. Untuk menghindari penilaian secara subjektif, peneliti menggunakan pengujian normalitas dengan Kolmogorov-Smirnov Test berikut:

Tabel 3. Uji Kolmogorov-Smirnov Test

\begin{tabular}{llr}
\hline & & Unstandardized Residual \\
\hline $\mathrm{N}$ & & 25 \\
Normal Parameters & Mean & $0 \mathrm{E}-7$ \\
& Std. Deviation & 1,67260112 \\
& Absolute & 173 \\
Most Extreme DifferencesPositive &, 173 \\
\multicolumn{2}{c}{ Negative } &,- 077 \\
Kolmogorov-Smirnov Z &, 866 \\
\hline
\end{tabular}




\author{
Unstandardized Residual \\ Asymp. Sig. (2-tailed) \\ , 442 \\ a. Test distribution is Normal. \\ b. Calculated from data.
}

Berdasarkan tabel 3 terlihat bahwa nilai Asymp.sig. (2-tailed) adalah 0,442 ini berarti nilainya di atas nilai signifikan 5\% (0,05). Dengan kata lain, variabel tersebut berdistribusi normal.

Tabel 4. Uji Linearitas

\begin{tabular}{|c|c|c|c|}
\hline \multicolumn{4}{|c|}{ ANOVA } \\
\hline \multirow{2}{*}{\multicolumn{4}{|c|}{$\begin{array}{ccr}\text { Sum of Squares dfMean Square } & \text { F } & \text { Sig. } \\
170,3025 & 34,06019,342,000\end{array}$}} \\
\hline & & & \\
\hline \multirow{4}{*}{ KepuasanPelanggan $*$ KualitasJasa } & Between GroupsLinearity & 136,6181 & $\begin{array}{r}34,06019,342,000 \\
136,61877,581,000\end{array}$ \\
\hline & Deviation from Linearity & 33,6844 & $8,4214,782,008$ \\
\hline & Within Groups & 33,45819 & 1,761 \\
\hline & Total & 203,76024 & \\
\hline
\end{tabular}

Hasil analisis menunjukkan bahwa pada tabel ANOVA nilai $\mathrm{F}$ pada deviation from linearity sebesar 4,782 dengan signifikansi 0,008, maka diperoleh kesimpulan bahwa nilai signifikan $\geq(0,008>0,05$, maka dari hipotesis yang diberikan H0 diterima. Artinya, kedua data saling berhubungan secara linier.

Tabel 5. Correlations

\begin{tabular}{llrr}
\hline & \multicolumn{3}{c}{ Kualitas Jasa Kepuasan Pelanggan } \\
\hline \multirow{3}{*}{ KualitasJasa } & Pearson Correlation & 1 &, $819^{* *}$ \\
& Sig. (2-tailed) & 25 &, 000 \\
$\mathrm{~N}$ & Pearson Correlation &, $819^{* * *}$ & 25 \\
KepuasanPelangganSig. (2-tailed) &, 000 & 1 \\
$\mathrm{~N}$ & 25 & 25 \\
$* *$ Correlation is significant at the 0.01 level (2-tailed).
\end{tabular}

Hasil pengujian di atas diperoleh nilai korelasi adalah 0,819 dimana terdapat korelasi antara variabel Kualitas Jasa (X) dengan Kepuasan Pelanggan (Y) yaitu positif atau dengan kata lain mempunyai hubungan positif.

Tabel 6. Interpretasi Koefisien Korelasi $r$

\begin{tabular}{cc}
\hline Interval Koefisien & Tingkat Hubungan \\
\hline $0,000-0,199$ & SangatRendah \\
$0,200-0,399$ & Rendah \\
$0,400-0,599$ & CukupKuat \\
$0,600-0,799$ & Kuat \\
$0,800-1,000$ & SangatKuat \\
\hline
\end{tabular}

Berdasarkan tabel 6 diatas menunjukan bahwa kontribusi variabel Kualitas Jasa mempengarui variabel Kepuasan Pelanggan dimana diperoleh korelasi r sebesar 0,819 berada pada interval 0,800-1,000, sehingga dapat disimpulkan bahwa variabel Kualitas Jasa memiliki hubungan sangat kuat terhadap variabel Kepuasan Pelanggan.

Tabel 7. HasilKoefisienDeterminasi $\mathrm{R}^{2}$

\begin{tabular}{lcrrr}
\multicolumn{5}{c}{ Model Summary $^{\mathbf{b}}$} \\
\hline Model & R & R Square & Adjusted R Square & Std. Error of the Estimate \\
\hline 1 & $.819^{\text {a }}$ & .670 & .656 & 1.709 \\
a. Predictors: (Constant), KualitasJasa & & \\
\hline
\end{tabular}

Pada tabel 7 mengenai hasil koefisien determinasi dapat diketahui bahwa:

a. R menunjukkan korelasi sederhana, yaitu variabel Kualitas Jasa terhadap variabel Kepuasan Pelanggan adalah sebesar 0,819 atau $81,9 \%$. Artinya hubungannya erat, semakin besar $\mathrm{R}$ berarti hubungannya semakin erat.

b. R square (R2) atau kuadrat R menunjukkan koefisien determinasi adalah sebesar 0,670 atau $67 \%$ dimana variabel Kualitas Jasa dapat menjelaskan variabel Kepuasan Pelanggan, sedangkan sisanya sebesar 33\% dijelaskan oleh variabel lain yang tidak diteliti oleh penelitian ini.

c. Untuk data variabel independen lebih baik menggunakan adjusted R2 yaitu sebesar 0,656 artinya 65,6\% variabel Kualitas Jasa dapat menjelaskan variabel Kepuasan Pelanggan, sedangkan sisanya 34,4\% dipengaruhi oleh variabel lain di luar penelitian ini.

d. Standard Error of The Estimated adalah ukuran kesalahan prediksi. Standard Error of The Estimated juga bisa disebut standar deviasi. Dalam kasus ini nilainya sebesar 1,709\%. Semakin kecil standar deviasi berarti model semakin baik. 
Tabel 8. Coefficients

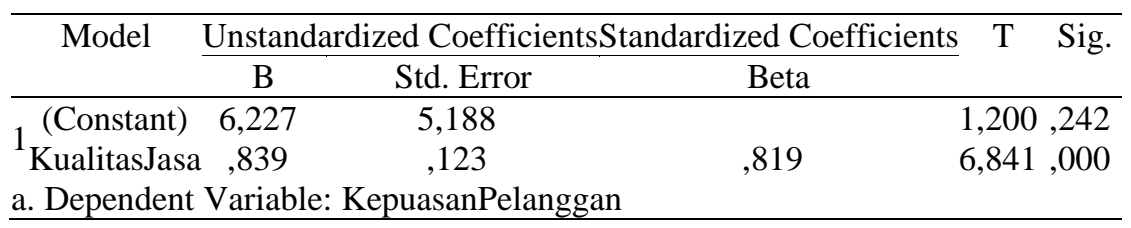

Pada tabel 8 menunjukkan bahwa perhitungan diperoleh nilai konstanta (a) 6,227 dan b sebesar 0,839, sehingga diperoleh persamaan regresi linier sederhana $\mathrm{Y}=6,227+0,839 \mathrm{X}+\mathrm{e}$, dimana variabel Kualitas Jasa mempunyai pengaruh yang signifikan terhadap variabel Kepuasan Pelanggan. Hal ini dapat dilihat dari keterangan sebagai berikut :

a. Konstanta (a) sebesar 6,227 menunjukkan bahwa tanpa adanya variabel Kualitas Jasa, besar nilai variabel Kepuasan Pelanggan Prima Elektronik adalah sebesar 6,227.

b. Kualitas Jasa (X) sebesar 0,839 menunjukkan bahwa variabel Kualitas Jasa cukup berpengaruh positif dan signifikan terhadap Kepuasan Pelanggan, artinya setiap terjadi peningkatan variabel Kualitas Jasa, maka akan berpengaruh positif terhadap peningkatan Kepuasan Pelanggan.

Berdasarkan hasil pengolahan data primer dengan bantuan program SPSS 24 for windows pada tabel 8 di atas maka diperoleh hasil uji $t$ nilai $t_{\text {hitung }}$ Kualitas Jasa 6,841 $>t_{\text {tabel }} 2,069$, maka Ha diterima karena nilai $t_{\text {hitung }}>t_{\text {tabel. }}$. Dengan demikian dapat disimpulkan bahwa secara parsial Kualitas Jasa (variabel bebas) berpengaruh positif terhadap Kepuasan Pelanggan (variabel terikat) di Prima Elektronik Medan.

\section{KESIMPULAN}

Berdasarkan berbagai pengujian dan analisis data, dari penelitian ini dapat diperoleh beberapa kesimpulan mengenai Kualitas Jasa Terhadap Kepuasan Pelanggan di Prima Elektronik, Medan yaituberdasarkan uji t diketahui bahwa hasil yang diperoleh dari Kualitas Jasa (X) memiliki nilai $t_{\text {hitung }} 6,841>t_{\text {tabel }} 2,069$, maka Ha diterima karena $t_{\text {hitung }}>t_{\text {tabel }}$, sehingga Kualitas Jasa secara parsial berpengaruh positif terhadap Kepuasan Pelanggan di Prima Elektronik Medan, berdasarkan uji regresi linier sederhana, maka diperoleh persamaan nilai konstanta sebesar 6,227 dan nilai b 0,839, sehingga diperoleh persamaan regresi linier sederhana $\mathrm{Y}=6,227+0,839 \mathrm{X}+\mathrm{e}$, dimana Kualitas Jasa mempunyai pengaruh yang signifikan terhadap variabel Kepuasan Pelangganserta nilai koefisien determinan (R2) diperoleh sebesar 0,670 atau 67\% yang berarti bahwa variabel Kualitas Jasa berpengaruh terhadap Kepuasan Pelanggan di Prima Elektronik Medan. Berdasarkan kesimpulan yang peneliti paparkan sebelumnya, maka peneliti memberikan saran berdasarkan dari hasil penelitian yaitu Prima Elektronik diharapkan untuk terus meningkatkan kualitas jasa agar dapat mencapai kepuasan pelanggan sehingga tercapai tujuan organisasi dan Prima Elektronik hendaknya lebih memperhatikan kualitas jasa sehingga dapat mencapai kepuasan pelanggan.

\section{DAFTAR PUSTAKA}

Anggraini, D., Dennius, D., Arwin, A., Ciamas, E. S., \& Wilinny, W. (2019). On The Job Training dan Off The Job Training Karyawan PT. Amir Hasan Medan. Jurnal Ilmiah Kohesi, 3(1), 118-123.

In Khurun, A. W., \& Asyik, N. F. (2019). Pengaruh kompetensi dan independensi terhadap kualitas audit dengan etika auditor sebagai variabel pemoderasi. 8(8), 1-15.

Indrasari, M. (2019). PEMASARAN DAN KEPUASAN PELANGGAN (Cetakan 1). Surabaya: Unitomo Press.

Rohaeni, H., \& Marwa, N. (2018). Kualitas Pelayanan Terhadap Kepuasan Pelanggan. 2(2), 312-318.

Setyo, P. E. (2017). PENGARUH KUALITAS PRODUK DAN HARGA TERHADAP KEPUASAN KONSUMEN "BEST AUTOWORKS." 1(6), 755-764.

Sulaiman, F. (2017). Desain Produk : Rancangan Tempat Lilin Multifungsi Dengan Pendekatan 7 Langkah Nigel Cross. Teknovasi, $4(1), 32-41$.

Tjiptono, F., \& Chandra, G. (2019). Service, Quality \& Customer Satisfaction (Edisi 5). Yogyakarta: Andi (Anggota IKAPI).

Weny, Nugroho, N., Anggraini, D., Sofian, \& Erwin. (2019). Analisis Pelaksanaan Pelatihan Dan Pendidikan Pada PT. Bimasakti Mahawira Medan. Seminar Nasional Teknologi Komputer \& Sains (SAINTEKS), 87-91.

Winata, A., \& Fiqri, I. A. (2017). LOYALITAS PELANGGAN HOTEL EMERSIA DI BANDAR. 03(02), 133-149.

Yuliana, Y., Lisa, L., Nancy, N., Chandra, W., \& Aigan, W. (2019). Analisis Penerapan Promosi Pada PT. Adam Dani Lestari Medan. Seminar Nasional Teknologi Komputer \& Sains (SAINTEKS), 106-108.

Zulkarnaen, W., \& Amin, N. N. (2018). PENGARUH STRATEGI PENETAPAN HARGA TERHADAP KEPUASAN KONSUMEN (STUDI TERHADAP REMA LAUNDRY DAN SIMPLY FRESH LAUNDRY DI JALAN CIKUTRA BANDUNG). 2(1). 